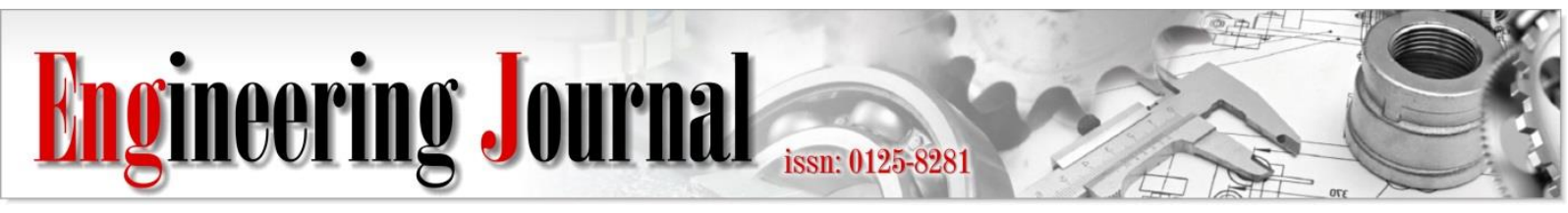

Article

\title{
Perceived Service Quality and Commuter Segmentation of Informal Public Transport Service in Bangkok, Thailand
}

\author{
Chutaporn Amrapala ${ }^{1, a}$ and Kasem Choocharukul ${ }^{2, \mathrm{~b}, *}$
}

1 Environment, Development, and Sustainability Program, Graduate School, Chulalongkorn University, Phayathai Rd., Pathumwan, Bangkok 10330, Thailand

2 Center of Excellence in Infrastructure Management, Department of Civil Engineering, Faculty of

Engineering, Chulalongkorn University, Phayathai Rd., Pathumwan, Bangkok 10330, Thailand

E-mail: aamrapala_chu@hotmail.com, bkasem.choo@chula.ac.th (Corresponding author)

\begin{abstract}
One informal public transport service in Bangkok is Silor (SR), given the meaning in Thai as four-wheeler. SR facilitates urban mobility both in terms of major travel mode and feeder to bus and mass transit lines in the city. This research aims to explore user subgroups characterized by attitudes through an Exploratory Factor Analysis followed by commuter segmentation through Cluster Analysis based on the obtained latent variables in order to propose future implications for SR service improvement in Bangkok. Interviews are conducted through questionnaire survey to collect users' socioeconomic and trip profiles and attitudes towards SR service. The result reveals dimensions of service quality, which explain user perception and priorities regarding the service. Four segments of SR users are identified by four attitudinal factors, including reliability, in-vehicle environment, comfort and convenience, and environmental impact. Personal profiles, trip characteristics, and attitudes of each segment are analyzed and compared. Research findings would contribute to new knowledge on quality factors and area of SR service improvement as well as provide better understanding on diverse perception among SR user segments. Policy implications that best suit for each user segments are discussed.
\end{abstract}

Keywords: Silor, attitudes, service quality, commuter segmentation, factor analysis, cluster analysis.

ENGINEERING JOURNAL Volume 23 Issue 6

Received 7 March 2019

Accepted 13 July 2019

Published 30 November 2019

Online at http://www.engj.org/

DOI:10.4186/ej.2019.23.6.1 


\section{Introduction}

The city of Bangkok is growing rapidly with the population approaching ten millions, resulting in an increase in travel demand and worsened the traffic congestion in the city. Such situation comes along with the challenges in terms of environmental pollution, quality of life, well-beings, as well as national economic development. However, many researchers and experts believe that public transport is the key instrument to overcome these problems. The provision of existing public transport services are facing challenges to maintain the current users and attract potential users. To improve public transport performance, comprehensive plans with the consideration on all dimensions of quality of service are required.

At present, various forms of public transport are seen in Bangkok, including both formal and informal services. Among them is Silor (SR), given the meaning in Thai as "four-wheeler". The vehicle is a small converted Daihatsu or Suzuki pickup with 6-11 passenger seats, as shown in Fig. 1. The seating structures were locally adapted and the seating capacity varies among each route. Based on the Department of Land Transport (DLT) database in 2018, 1,964 of SR are registered and 143 service routes have been operating in Bangkok [1]. Such transport mode is classified as informal because not all vehicles and drivers are properly registered in accordance with public transport service regulation. The operational issues concerning vehicle capacity, fare structure, and station area are poorly regulated. Many service routes are not conformed to those recorded by DLT, illegal route operations are observed, such as route extension and unauthorized routes [2]; nonetheless, SR service gains popularity from people in the neighborhood both as the main travel mode and as feeders to access a more formal mode, such as bus and mass transit lines in Bangkok. Although SR is known to cause pollution, congestion and accidents in the area, its provision of mobility for users are of high interest among transport researchers.

In previous studies, a report by DLT and Transport Institute (TRI) [3] investigated SR demand, supply, and analysis in safety, route alignment, laws and regulation aspects. Another research was on attitudes of SR passengers [2]. Former studies on SR in Bangkok are very limited; however; various literatures on informal transport in Asian developing countries particularly the similar functioning modes as SR are available, for instance, Angkot, Motodup and Remork, Songtaew and Jeepney [4-7]. Thus, it is important to examine the perceived service quality from SR users as well as the effect of different service quality on their satisfaction.

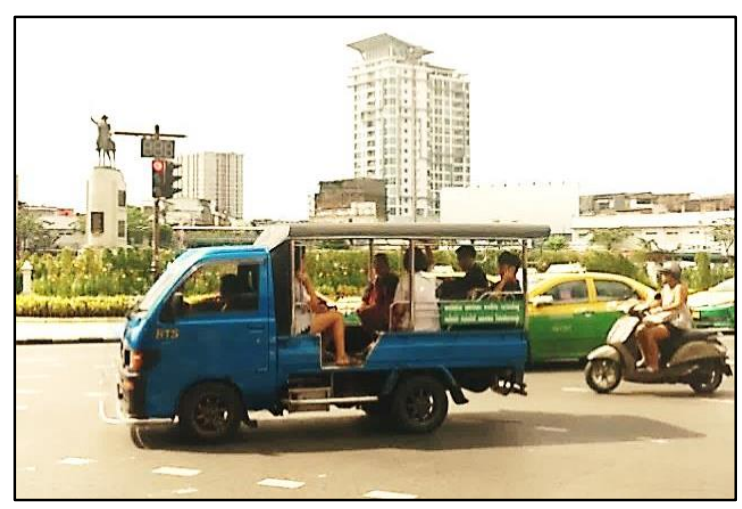

Fig. 1. Silor in Thailand.

The objective of the present study is to explore users' perceptions regarding SR service quality and present SR user subgroups characterized by users' attitudes through Exploratory Factor Analysis (EFA) followed by Cluster Analysis (CA) based on the obtained latent variables. The goal is to propose future implications for SR service improvement in Bangkok. Subsequently, two research questions are addressed: - What are the service quality factors affecting the overall satisfaction of SR service?

- What are different attitudes perceived by different user segments?

This paper applies EFA to extract latent variables of service attributes based on user survey of two SR routes in Bangkok. Logistic regression analysis is performed to investigate the casual relationship between the perception of service quality factors as independent variables and overall satisfaction as dependent variables. In order to identify user subgroups, market segmentation is performed to classify users into 
segments having similar features. Then, socioeconomic, travel profiles and attitudes of each user subgroups are cross-analyzed to understand interaction among significant variables.

Research findings would contribute to new knowledge on quality factors, area of improvements of SR service and their effects on overall satisfaction of users. In addition, the study would provide better understanding to policy makers on diverse perceptions of different user segments. Then, the appropriate development plan can be set up to best serve heterogeneous user groups in each SR route. Furthermore, the proposed policies would not only provide the society with high quality of public transport services in response to the rising travel demand, but also encourage the use of SR as an efficient alternative for a more sustainable means of travelling.

The organization of this paper starts with a literature review on attitudes towards transit service quality and market segmentation (Section 2). The methodology is presented in Section 3, which describes study area, data preparation, and statistical analysis. In Section 4, the result of EFA, regression analysis and CA are presented and the findings are discussed in Section 5. The paper then summarizes the main findings in Section 6.

\section{Literature Review}

Service quality is a measure of how well the service level that is delivered matches customer expectations, while delivering quality service means conforming to customer expectations on a consistent basis [8]. Perceptions about different characteristics of the service are very different among users. Users' perceptions are heterogeneous because the qualitative nature of some public transport service aspects, the different users' socioeconomic characteristics, and the diversity in the tastes and attitudes towards public transport [9]. Several researchers have argued that travel behavior is greatly influenced by individuals' personality, perceptions and attitudes. Ajzen [10] proposed the Theory of Planned Behavior based on the concepts of attitudes, perception of social norms, and perceived behavioral control. Attitudes can be defined as positive or negative evaluations or beliefs about something that, in turn, may influence individual's behavior. Recognizing people's attitudes provide a useful guide to their likely behavior since attitudes seem to influence intentions to act [11].

This study particularly focuses on users' attitudes towards an informal public transport mode. The mode is also known as LAMAT, Locally Adapted, Modified, and Advanced Transport, which is the common definition for all paratransit services in Asian developing countries [12]. Extensive literatures are available on users' attitudes towards service quality associated with formal public transport modes; nevertheless, research on LAMAT service quality examining user perceptions and segmentation is very limited. In the context of paratransit in Thailand, Choocharukul and Sriroongvikrai [2] conducted a survey on attitudes of passengers with two available modes, one is SR and the other is motorcycle taxi, bus or Songtaew. Respondents were asked to indicate importance and satisfaction scores, form 1-5 scale, on seven aspects, including wait time, travel time reliability, travel speed, travel cost, seat comfort, stopping location, and safety. The different scores of each paired transport modes illustrated that when considering between SR and mortorcycle taxi, the former is more advantageous for its fare and safety, whereas the advantage of the latter are speed and stopping location. Comparing to bus, SR is more advantageous in terms of lower fare and higher speed. However, the study found that some preferred bus due to the higher perception of safety. For the case of SR and Songtaew, the preference towards the former is as of the speed, while the latter are due to lower total trip cost.

Additionally, attitudinal variables are evaluated from the perspective of users and grouped into latent factors as a study on influences of informal transport mode on mass transit connectivity by Tangphaisankun et al. [6]. The performed factor analysis classified service measurements into four main factors. Firstly, mass transit access measurement included total access time, total wait time, total access cost, and transfer difficulty. Secondly, comfort and convenience can be measured by wait time, number of stops, and flexibility to change route. The third factor is safety and security of transport mode, measured by riding or driving quality, vehicle condition and safety equipment, and night time security from crime. The last factor is information of service, including service schedule and fare information, service and registration information, and accident insurance information. Further, the effects of commuters' satisfaction to attitudes were analyzed among three commuter segments of different income levels, low, middle and high income. The model illustrated that satisfaction has positive effects on mass transit access trip. Result also revealed that time of access trip to stations is significant factor for middle and high income groups, while the expense and wait time for access trips are significant for both low and middle income commuters. 
In Bangladesh, the paratransit users were interviewed with structured questionnaire to develop empirical modes using 24 service quality variables [13]. The physical appearance and service features are found to be the two latent variables from the analysis. In addition, the study revealed that physical appearance have less influence than service features on the overall service quality. The result found that punctuality and reliability, fitness of vehicle and travel costs are the most significant observed variables having influence on the service.

In the case of informal transport in Indonesia, a service quality model was tested by Bakti and Sumaedi [14]. Four dimensions of service quality were extracted. The first dimension is comfort, measured by six indicators including passenger capacity, safety, obedience to traffic, comfortable temperature, security, and safety related to other passenger behavior. Secondly, the tangible dimension represented the cleanliness of interior, exterior, condition of public transport machine, and seat conditions. The third aspect is personnel which related to four indicators, including helpfulness, responsiveness, understanding passenger needs, and courtesy. Lastly, the reliability dimension, measured through wait time, travel time, adequacy of service, and delivery to destination. The result of service quality measurement are helpful in monitoring the service performance and further can be used to develop management strategies in order to increase the ridership and provide efficient public transport service quality to the community.

Further, the study of different transport modes in India by Sarkar and Mallikarjuna [15] highlighted that attitudes and perceptions affect the mode choice behavior of commuters. The household survey was conducted with city residents on perceptions towards car, bus, three wheeler, two wheeler, bicycle, cycle rickshaw and walking mode. Service indicators were grouped into four latent variables, namely, comfort, safety, flexibility, and reliability. The result illustrated the underlying latent attitudes towards different travel modes in that comfort and flexibility were found to be significant factors affecting trip makers' mode choice behavior. Flexibility significantly increases the propensity to choose two wheeler and three wheeler modes whereas the desire for comfort was found to increase the tendency to use car as a mode of travel.

The literature also revealed that public perception research can be implemented as the national action plans [16]. In order to improve safety and security in public transport services, understanding and awareness of users and drivers on road safety and security issues are the most important factor. They should be informed, trained and educated in an effective way. Based on the perception of stakeholders, an improvement agenda has been developed consisting of three aspects, including technology, management, and institutions. The agenda has been clarified by a set of action plans, indicating involved parties and timeframe as to implement the action draft for road safety.

Basic ideas on market segmentation have been found in in travel behavior area. For instance, market segmentation approach was used to identify the potential transit markets [17]. Travelers were clustered into eight groups by three attitudinal factors including the sensitivity to time, need for fixed schedule and willingness to use public transit. Market segmentation is also useful in developing strategies to best serve the various submarkets for increasing public transport ridership [17]. Previous studies show that market segmentation analysis is a means of increasing the share of public transport modes.

Table 1 provides a summary of case studies in literatures. They explored service attributes by applying comparative, factor, and cluster analysis as well as structural equation modeling and choice modeling. For each mode of transport, previous studies explained user perceptions in a single context; there is still a lack of understanding on how users from different service areas perceived the quality of service. Therefore, our research is conducted in two route contexts and provides complementary insights on heterogeneity of users based on perception analysis and market segmentation approaches.

Table 1. Informal transport case studies in literatures.

\begin{tabular}{|c|c|c|c|c|c|}
\hline Authors & Year & Country & Mode & Techniques & Attributes \\
\hline $\begin{array}{l}\text { Choocharukul and } \\
\text { Sriroongvikrai }\end{array}$ & 2011 & Thailand & $\begin{array}{l}\text { Silor, Motorcycle taxi, } \\
\text { Bus, Songtaew }\end{array}$ & - Comparative analysis & $\begin{array}{l}\text { - Wait time, travel time, travel speed, travel } \\
\text { cost, seat comfort, stopping location, and safety }\end{array}$ \\
\hline Tangphaisankun et al. & 2009 & Thailand & $\begin{array}{l}\text { Motorcycle taxi, } \\
\text { Songtaew }\end{array}$ & $\begin{array}{l}\text { - Factor analysis } \\
\text { - Structural equation } \\
\text { modeling }\end{array}$ & $\begin{array}{l}\text { - Mass transit access, comfort and } \\
\text { convenience, safety and security, and } \\
\text { information }\end{array}$ \\
\hline Rahman et al. & 2016 & Bangladesh & Paratransit & $\begin{array}{l}\text { - Structural equation } \\
\text { modeling }\end{array}$ & - Physical appearance and service features \\
\hline Bakti and Sumaedi & 2015 & Indonesia & Paratransit & - Factor analysis & - Comfort, tangible, personnel, and reliability \\
\hline Sarkar and Mallikarjuna & 2018 & India & $\begin{array}{l}\text { Formal and informal } \\
\text { transport }\end{array}$ & - Mode choice model & - Comfort, safety, flexibility, and reliability \\
\hline Joewono and Kubota & 2006 & Indonesia & Paratransit & - Factor analysis & - Safety and security \\
\hline Tarigan & 2014 & Indonesia & Paratransit & - Cluster analysis & $\begin{array}{l}\text { - On-time performance, security, and service } \\
\text { satisfaction }\end{array}$ \\
\hline
\end{tabular}




\section{Methodology}

\subsection{Study Area}

In this study, Bangkok, the capital city located in the central part of Thailand, has been chosen as the study area. Bangkok is divided into 50 districts mainly for administrative purposes. We aim to compare user characteristics and attitudes among SR service in two areas of Bangkok, namely, West and East, which are distinct in socioeconomic characteristics. Therefore, we intentionally select one SR route from each area. Both of them are operated as fixed routes with flat fare. We admit that findings in our study might not be applied to all SR routes in Bangkok as there exist different forms of SR services, including fixed or non-fixed route and flat fare or upon negotiation.

Two SR routes were investigated in the study: West Bangkok (BKK) and East BKK. For West BKK, BangbonTaladplu route is selected as a case study, of which the service span covering three districts, i.e. Bangbon, Chomthong, and Thonburi. In the case study of East BKK, Vibhavadirangsit-Ratchadapisek route is chosen, serving Chatuchak and Dindaeng district areas. The two routes are chosen in this research as they have been serving the demands in districts of high population density. Bangkok districts map with the alignments of the two routes is illustrated in Fig. 2.

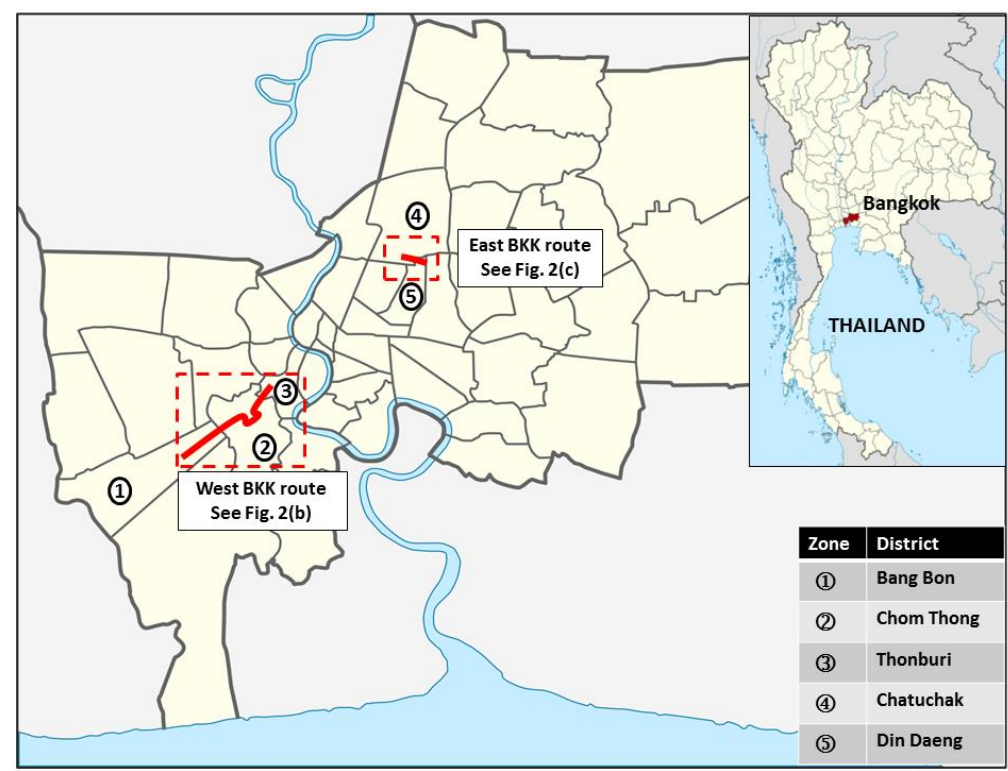

(a)

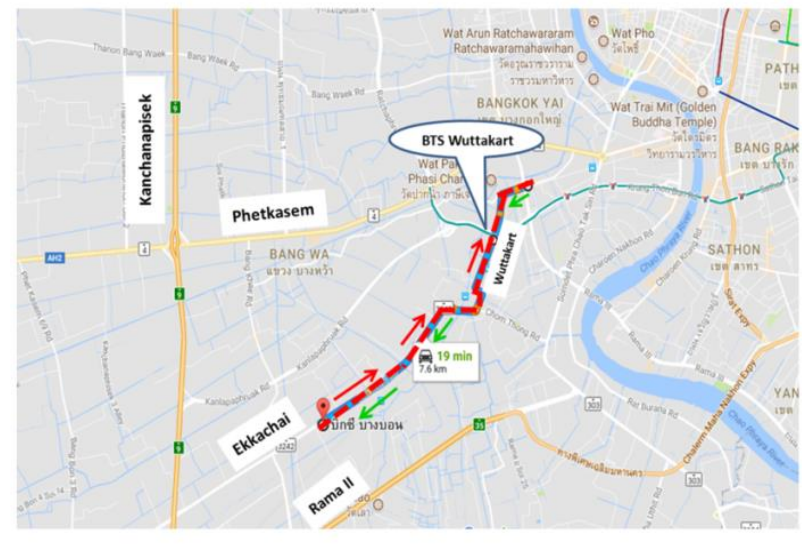

(b)

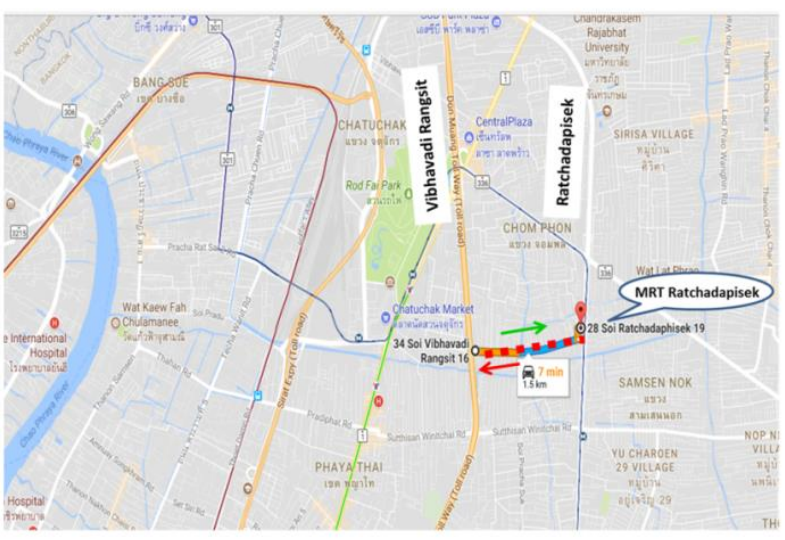

(c)

Fig. 2. Map of Bangkok districts (a) showing locations of West BKK route (b) and East BKK route (c).

The characteristics of each route are presented in Table 2, including population of each district with population density, average income, and the connecting transport modes. The West BKK route runs through industrial zone, commercial zone, medium and high-density residential zone. For the East BKK, the route 
operates in the high-density residential zone. Both routes connect with mass transit lines, which is BTS sky train Wuttakart station for West BKK route and MRT subway Ratchadapisek station for East BKK route. The length of the service routes are approximately 8 kilometers for West route and 2 kilometer for East route.

Table 2. Characteristics of route location.

\begin{tabular}{llllll}
\hline Route & District & Populationa & $\begin{array}{l}\text { Population density } \\
\left.\text { (people } / \mathrm{km}^{2}\right)^{\mathrm{a}}\end{array}$ & $\begin{array}{l}\text { Income (Baht/month) } \\
\text { Mean (SD) }\end{array}$ & $\begin{array}{l}\text { Connecting to other transport } \\
\text { modes }\end{array}$ \\
\hline West BKK & (1) Bangbon & 107,397 & 3,091 & $10,761(578)$ & $11,161(654)$ \\
& (2) Chomthong & 155,048 & 5,903 & $10,030(533)$ & $\begin{array}{l}\text { BTS sky train Silom Line } \\
\text { (Wuttakart Station) }\end{array}$ \\
& (3) Thonburi & 113,338 & 13,254 & $13,060(571)$ & MRT subway Blue Line \\
East BKK & (4) Chatuchak & 159,514 & 4,847 & $11,701(443)$ & (Ratchadapisek Station) \\
& (5) Dindaeng & 125,964 & 15,078 & &
\end{tabular}

\subsection{Data Collection}

SR trip data were collected through customer satisfaction survey conducted in West and East BKK routes. SR users are interviewed by means of survey questionnaires during July-August 2018. The survey team of 3-4 members approached SR users randomly on-board and off-board at various points along the two routes, such as SR stations, bus stops, convenience stores, and restaurants.

A pilot survey was conducted and several confusing questions were redesigned according to user feedbacks. The final questionnaire structure is classified into three sections. In the first section, SR trip characteristics have been collected, including frequency of use, need of transfer, travel alone or with companions, availability of alternative mode, travel distance, travel time, and overall satisfaction of the service have been collected. The second section consisted of respondents' rating on level of satisfaction towards different service dimensions. The five-point Likert-scale was applied to 16 attitudinal statements, ranging from 1 (strongly disagree) to 5 (strongly agree). The statements are significant attributes derived from previous research on perceptions towards different transport modes [20-24]. Lastly, the information related to socioeconomic status, covering, gender, age, marital status, education level, and income have been collected. The approximate time to finish all three sections in the questionnaire is 5 to 10 minutes.

\subsection{Analytical Tools}

Traveller attitudes are often unobservable and cannot be directly measured. However, in previous research, factor analysis has been commonly used in identifying latent variables from a series of attitudinal statements or questions. A considerable number of researchers performed EFA to identify the dimensions of public transport service quality from various service indicators [25-28]. A great number of literatures applied the identified latent variables from EFA to perform market segmentation [28]. Several studies evaluated the use of statistical cluster methods such as K-means clustering to segment the travel market [29, 30]. K-means cluster uses the within-cluster variations as a measure to form homogeneous cluster. Specifically the procedure aims at partitioning the data in such a way that the within cluster variation is minimized [31].

In this study, the dataset is separated into West BKK and East BKK routes for the factor to be analyzed. The data are further combined before performing cluster analysis to interpret results of the SR system as a whole. Firstly, the EFA is applied to extract underlying latent variables in the 16 attitudinal variables. The factor loadings were then estimated using Principal Component Analysis (PCA) [32]. To enable easy interpretation, the factors were rotated using the Varimax technique [33] so that each variable loaded heavily onto a single factor. This help in the clear identification of variables that measured each factor, and minimized the overlap across factors. The reliability of scales have also been tested covering the Kaiser Meyer Olkin (KMO) test of sampling adequacy, Bartlett's test of Sphericity and Cronbach's alpha test of internal consistency. KMO measure is a ratio of the sum of squared correlations to the sum of squared correlations plus sum of squared partial correlations. The value approaches 1 if partial correlations are small. Values of 0.6 and above are required for good FA [34]. Then, a regression model is conducted on the constructs identified in factor analysis, as independent variables, to explain variance in overall satisfaction of the service. As parameter of satisfaction is measured on sequential scale, the ordinal logistic regression is applied.

After factor analysis and regression analysis, clustering method is performed to divide commuters into heterogeneous groups showing homogeneous features within each subgroup. The study selects the variables that are useful for interpretation and initially uses hierarchical clustering method to determine appropriate number of clusters [35]. Then applies the numbers of cluster solutions obtained as an input to K-means 
clustering method. Results from clustering method are carefully examined to obtain meaningful subgroups. Finally, cross-analysis of socioeconomic characteristics, trip profiles, and attitudes is performed to understand which variables play relevant role in differentiating the obtained clusters.

\section{Results}

\subsection{User Characteristics and Trip Profiles}

The dataset from questionnaire interviews conducted in July-August 2018 is analyzed based on a total of 242 valid respondents after excluding samples with missing key information. The dataset is separated into two groups, 125 individuals are users from West BKK and 117 are from East BKK route. Summary of descriptive statistics of user characteristics and trip profiles are shown in Table 3.

Table 3 Descriptive statistics of dataset.

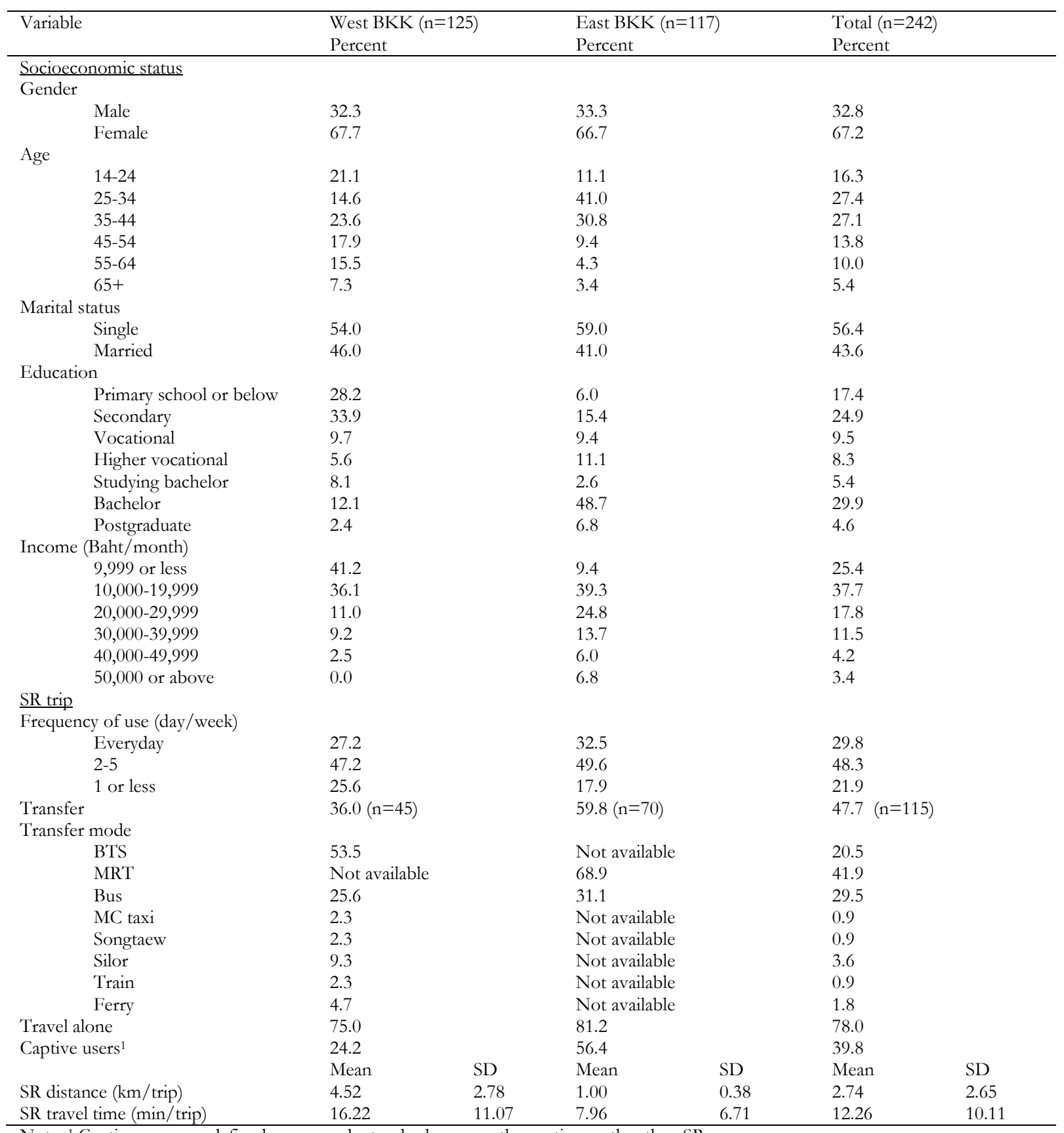


In brief, both routes share common features in that the majority of users are female, single, travelling alone and uses SR more than once per week. The higher share of female SR users is in line with previous study by DLT and TRI [3] which revealed 65\% female SR users. However, the differences among their characteristics are revealed. For East BKK route, most users are in the middle-age, between 25-44 years, while users from West BKK are widely distributed in all age groups. The higher proportion of users with the monthly income over 20,000 Baht are found in East BKK. The similar evidence is also found in terms of university graduates in the East route. When compared to West BKK route, higher proportions of users are captive riders and need to transfer for the case of East BKK route. Due to the longer route length of West BKK route, longer distance traveled and longer travel time are observed. Fig. 3 presented the comparison among dominant characteristics of users from West and East BKK routes.

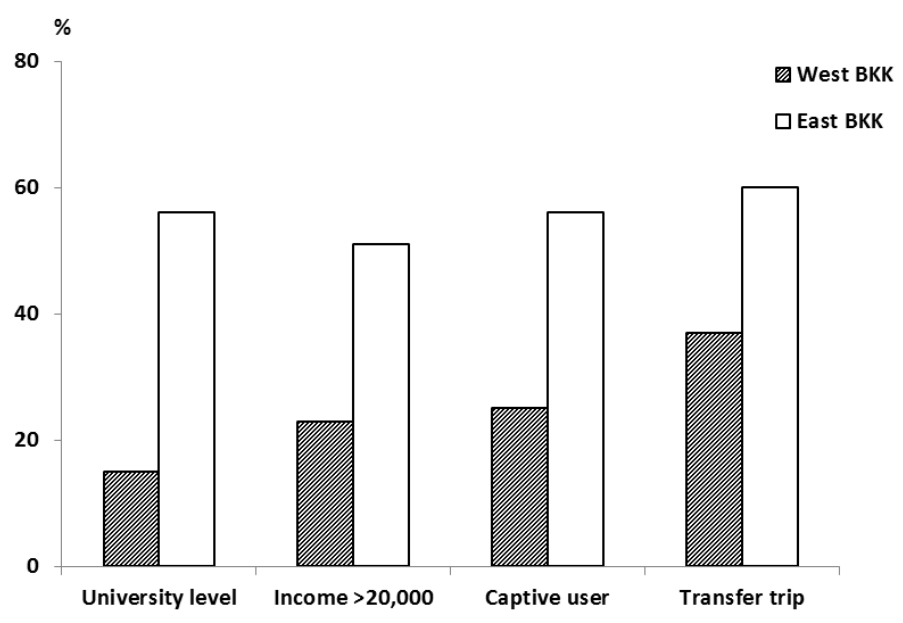

Fig. 3. Comparison among dominant characteristics of users from West and East BKK routes.

\subsection{Exploratory Factor Analysis}

Respondents were asked to rate the level of satisfaction towards different service dimensions and overall satisfaction of the service. Five-point Likert-scale was applied to 16 attitudinal statements and overall satisfaction level, ranging from 1 (strongly disagree) to 5 (strongly agree). Descriptive statistics from both routes are shown in Table 4 . The statistical tests reveal significant mean differences in most variable scores and, therefore, support our hypothesis.

Table 4. Attitudinal variable and overall satisfaction score.

\begin{tabular}{|c|c|c|c|c|c|c|c|c|}
\hline \multirow[t]{2}{*}{ No. } & \multirow[t]{2}{*}{ Variables } & \multicolumn{2}{|c|}{$\begin{array}{l}\text { West BKK } \\
(\mathrm{n}=125)\end{array}$} & \multicolumn{2}{|c|}{$\begin{array}{l}\text { East BKK } \\
(\mathrm{n}=116)\end{array}$} & \multicolumn{2}{|c|}{$\begin{array}{l}\text { Total } \\
(n=241)\end{array}$} & \multirow[t]{2}{*}{$\mathrm{p}$ value $^{1}$} \\
\hline & & Mean & SD & Mean & SD & Mean & SD & \\
\hline 1 & SR has frequent service & 4.30 & 0.89 & 4.52 & 0.55 & 4.41 & 0.75 & $0.025^{*}$ \\
\hline 2 & I am satisfied that SR routes cover places I want to go & 4.18 & 0.86 & 4.36 & 0.58 & 4.27 & 0.74 & 0.058 \\
\hline 3 & SR operates in the time period I need to travel & 4.02 & 0.94 & 4.40 & 0.63 & 4.20 & 0.83 & $0.000 * *$ \\
\hline 4 & Travelling by SR is fast and I can save my time & 4.12 & 0.88 & 4.53 & 0.63 & 4.32 & 0.79 & $0.000 * *$ \\
\hline 5 & I do not have to wait for SR for long time & 4.19 & 0.95 & 4.50 & 0.68 & 4.34 & 0.84 & $0.004^{* *}$ \\
\hline 6 & I always get a seat when riding SR and the seat is comfort & 4.06 & 0.94 & 4.33 & 0.67 & 4.19 & 0.83 & $0.011 *$ \\
\hline 7 & Shelter and benches at stops are available & 3.78 & 1.06 & 3.76 & 1.10 & 3.77 & 1.08 & 0.855 \\
\hline 8 & SR gives sufficient stop time to board and alight and it is easy to enter the vehicle & 3.75 & 1.03 & 4.11 & 0.86 & 3.93 & 0.97 & $0.003^{* *}$ \\
\hline 9 & It is convenient to connect with and transfer to other modes & 3.85 & 1.01 & 4.26 & 0.72 & 4.05 & 0.90 & $0.000 * *$ \\
\hline 10 & Riding SR is safe from road accident and secured from criminal incidents & 3.30 & 1.09 & 3.77 & 0.77 & 3.53 & 0.97 & $0.000^{* *}$ \\
\hline 11 & $\begin{array}{l}\text { SR is clean, free from dust or garbage, seat are in good condition } \\
\text { easy to move, protected from exposure to the elements }\end{array}$ & 3.17 & 1.13 & 3.65 & 0.79 & 3.40 & 1.01 & $0.000^{* *}$ \\
\hline 12 & Passengers riding SR are polite & 3.53 & 0.96 & 3.87 & 0.67 & 3.69 & 0.85 & $0.001 * *$ \\
\hline 13 & SR drivers are polite and honest & 3.48 & 1.08 & 3.85 & 0.77 & 3.66 & 0.96 & $0.002^{* *}$ \\
\hline 14 & SR causes air and noise pollution & 3.26 & 0.97 & 3.05 & 0.86 & 3.16 & 0.92 & 0.085 \\
\hline 15 & SR causes traffic congestion & 3.26 & 1.11 & 2.83 & 1.02 & 3.05 & 1.09 & $0.003^{* *}$ \\
\hline \multirow[t]{2}{*}{16} & SR causes road accidents & 3.02 & 1.06 & 2.72 & 1.03 & 2.88 & 1.05 & $0.026^{*}$ \\
\hline & Overall satisfaction & 3.74 & 0.79 & 3.95 & 0.67 & 3.84 & 0.74 & $0.030 *$ \\
\hline
\end{tabular}


EFA are performed separately on West and East BKK routes. For East BKK route, the attitudinal variable 5, which covers perceptions of wait time, cross-loads on two factors and is uninterpretable. Costello and Osborne [36] suggested that cross-loading items can be dropped if it compromises the integrity of the data. After attitudinal variable 5 is removed from East BKK route, each construct appeared to be distinct in the underlying attitudinal variables. All factor loadings exceed 0.4, no cross-loadings, and no factors with less than three variables [36]. The constructs arbitrarily are labeled in accordance with the content of component variables.

Table 5 presents the factor analysis results of West BKK and East BKK routes showing latent constructs, statement groupings, and factor loadings. EFA of both routes similarly demonstrate that four latent variables were extracted, Reliability, In-vehicle environment, Comfort and convenience, and Environmental impact. In West BKK route, 16 attitudinal statements explain $63.3 \%$ of the total variance, whereas in East BKK route, total 15 attitudinal statements explain $61.7 \%$ of the total variance. It is noted that in both routes, each latent factor grouped similar sets of the underlying aspects despite the variable 5 dropped off in East BKK route. Reliability explains the highest total variance in both routes, $20.8 \%$ and $17.0 \%$ for West BKK and East BKK routes, respectively.

Table 5. Exploratory factor analysis of service quality indicator with latent constructs, attitudinal statements groupings, and construct loadings.

\begin{tabular}{|c|c|c|c|c|c|c|c|c|}
\hline \multirow[t]{2}{*}{ Attitudinal variables } & \multicolumn{2}{|c|}{$\begin{array}{l}\text { Factor } 1 \\
\text { Reliability }\end{array}$} & \multicolumn{2}{|c|}{$\begin{array}{l}\text { Factor } 2 \\
\text { In-vehicle } \\
\text { environment }\end{array}$} & \multicolumn{2}{|c|}{$\begin{array}{l}\text { Factor } 3 \\
\text { Comfort and } \\
\text { convenience }\end{array}$} & \multicolumn{2}{|c|}{$\begin{array}{l}\text { Factor } 4 \\
\text { Environmental } \\
\text { impact }\end{array}$} \\
\hline & West & East & West & East & West & East & West & East \\
\hline SR has frequent service & 0.847 & 0.791 & & & & & & \\
\hline I do not have to wait for SR for long time & 0.763 & & & & & & & \\
\hline I am satisfied that SR routes cover places I want to go & 0.743 & 0.862 & & & & & & \\
\hline Travelling by SR is fast and I can save my time & 0.731 & 0.548 & & & & & & \\
\hline SR operates in the time period I need to travel & 0.711 & 0.760 & & & & & & \\
\hline Passengers riding SR are polite & & & 0.868 & 0.898 & & & & \\
\hline SR drivers are polite and honest & & & 0.828 & 0.737 & & & & \\
\hline $\begin{array}{l}\text { SR is clean, free from dust or garbage, seat are in good condition, } \\
\text { easy to move, protected from exposure to the elements }\end{array}$ & & & 0.645 & 0.657 & & & & \\
\hline Shelter and benches at stops are available & & & & & 0.787 & 0.568 & & \\
\hline SR gives sufficient stop time to board and alight and it is easy to enter the vehicle & & & & & 0.625 & 0.755 & & \\
\hline It is convenient to connect with and transfer to other modes & & & & & 0.551 & 0.621 & & \\
\hline Riding SR is safe from road accident and secured from criminal incidents & & & & & 0.551 & 0.688 & & \\
\hline I always get a seat when riding SR and the seat is comfort & & & & & 0.542 & 0.441 & & \\
\hline SR causes traffic congestion & & & & & & & 0.832 & 0.892 \\
\hline SR causes air and noise pollution & & & & & & & 0.826 & 0.765 \\
\hline SR causes road accidents & & & & & & & 0.813 & 0.904 \\
\hline Total variance explained $(\%)$ & 20.8 & 17.0 & 15.7 & 12.2 & 13.6 & 16.7 & 13.2 & 15.8 \\
\hline
\end{tabular}

\subsection{Logistic Regression Analysis}

The latent constructs of EFA are further analyzed to determine the degree to which attitudes towards SR quality of service influence the overall satisfaction with the service. Ordinal logistic regression is conducted separately for West BKK and East BKK route applying the overall satisfaction as the dependent variable, while the independent variables involve the latent constructs associated with the perception of SR service.

Logistic regression models estimate the log odds of the outcome occurring versus the log odds of the outcome not occurring for a given independent variable. These log odds ratios are functions of the probabilities. Assume that each case has a probability of having experiencing an event, defined as $p_{i}$. Since the dependent variable has values of only 0 and 1 , this $p_{i}$ must be estimated to treat the outcome in terms of probabilities. The value of 1 means the expected event occurs whereas the value of 0 means the expected event fails to occur. The logit transformation involves two steps [37]. First take the ratio of $p_{i}$ to $1-p_{i}$, or the odds of experiencing the event. Second, take the natural logarithm of the odds. The logit thus equals Eq. (1)

$$
L_{i}=\ln \left[\frac{p_{i}}{1-p_{i}}\right]
$$


The logit model solves problems in Eq. (2) and Eq. (3)

$$
\begin{gathered}
\ln \left[\frac{p}{1-p}\right]=\alpha+\beta x+e \\
{\left[\frac{p}{1-p}\right]=\exp (\alpha+\beta x+e)}
\end{gathered}
$$

where:

$p=$ Probability of an outcome event (overall satisfaction)

$\alpha=$ Intercept

$\beta=$ Estimated coefficient

$x=$ Independent variable (attitudinal scores towards reliability, in-vehicle environment, comfort and convenience, and environmental impact)

$e=$ Error term

Ordinal Logistic Regression (OLR) is an extension of logistic regression when there is an ordered outcome variable. In OLR, log odds ratios are calculated for the independent variable just as in logistic regression and are also calculated for the intercept of each level of the outcome variable. These intercept $\log$ odds ratios effect the change in the log odds associated with membership in a different level of the outcome variable compared to either the highest or lowest category. The relationship between the predictors and each of the levels of the outcome are proportional. Rather than estimating the probability of a single category, OLR estimates a cumulative probability, i.e. the probability that the outcome is equal to or less than the category of interest.

Equation (4) illustrates the general logit regression model:

$$
\operatorname{Logit}(p)=\ln \left[\frac{p}{1-p}\right]
$$

The models of OLR for West BKK and East BKK route are presented in Table 6. The model for West BKK route shows the differences in explaining variance in overall satisfaction of SR customers with a significant chi-square and the Nagelkerke pseudo $\mathrm{R}^{2}$ of 0.219 . Two constructs show significant effect over the satisfaction. First, Reliability reveals the highest coefficient, signifying that SR service frequency, service area, operation period, wait time, and travel time are major aspects in evaluating the overall satisfaction of SR customers. The second latent construct, still with significant effect, shows smaller coefficients, indicating that perceptions of In-vehicle environment and are minor attributes in satisfaction evaluation. The last two constructs have no significant effect over the satisfaction, suggesting that Comfort and convenience and Environmental impact of the service is not concerned in the evaluation of customers' overall satisfaction.

Table 6. Ordinal logistic regression analysis of overall satisfaction and attitudes towards service quality.

\begin{tabular}{lcccccc}
\hline Variable & \multicolumn{2}{l}{ West BKK route } & \multicolumn{3}{c}{ East BKK route } \\
& Estimates & S.E. & p value & Estimates & S.E. & p value \\
\hline Intercept & & & & & & \\
Overall satisfaction $=2.00$ & 3.257 & 1.389 & $0.019^{*}$ & 4.353 & 2.338 & 0.063 \\
Overall satisfaction $=3.00$ & 5.774 & 1.425 & $0.000^{* *}$ & 7.390 & 2.310 & $0.001^{* *}$ \\
Overall satisfaction $=4.00$ & 8.425 & 1.537 & $0.000^{* *}$ & 10.996 & 2.473 & $0.000^{* *}$ \\
\hline Reliability & 0.777 & 0.284 & $0.001^{* *}$ & 1.030 & 0.466 & $0.027^{*}$ \\
In-vehicle environment & 0.549 & 0.236 & $0.020^{*}$ & 0.030 & 0.362 & 0.933 \\
Comfort and convenience & 0.280 & 0.308 & 0.363 & 1.579 & 0.441 & $0.000^{* *}$ \\
Environmental impact & 0.108 & 0.201 & 0.590 & -0.670 & 0.238 & $0.005^{* *}$ \\
\hline -2LL (intercept) & 289.456 & & & 230.396 & & \\
-2LL (final) & 261.944 & & & 192.993 & & \\
Chi square (df=4) & $27.512^{* *}$ & & & $37.403^{* *}$ & & \\
Nagelkerke pseudo $\mathrm{R}^{2}$ & 0.219 & & & & & \\
** $\mathrm{p}<0.01 ; * \mathrm{p}<0.05$ & & & & & &
\end{tabular}


For East BKK route, the model reveals that differences in explaining variance in overall satisfaction exist with a significant chi-square and the Nagelkerke pseudo $\mathrm{R}^{2}$ of 0.318 . This suggests that the model accounts for one-third of the variation in overall satisfaction level. The increase in perceived Comfort and convenience would significantly raise overall satisfaction level, meaning that boarding and alighting, seat availability and comfort, suitability for transfer, amenities at stops, safety and security are the main attributes used to evaluate the overall satisfaction level. Although with significant effect, the perception towards Reliability has less impact on the satisfaction. On the contrary, the model illustrates that Environmental impact perception affect satisfaction level in different way. The more the perceived environmental impact of the mode, the less overall satisfaction was found. As the last latent variable, In-vehicle environment has no significant effect on satisfaction level, suggesting that customers are less concerned on the issue.

Interestingly, the factor analysis performed separately in two routes reveal the similar result in that the four underlying latent constructs, which are reliability, in-vehicle environment, comfort and convenience, and environmental impact; nonetheless, logistic regression model illustrated that there exist the differences in degree of effect for each aspects on the overall satisfaction.

\subsection{User Segmentation}

Clustering method is performed to divide users into heterogeneous groups showing homogenous features within each subgroup. Five variables are selected to perform user segmentation through K-means clustering method, including three latent constructs i.e. reliability, in-vehicle environment, and environmental awareness, and two socioeconomic variables, i.e. income and education. The appropriate number of clusters is determined by Elbow Criterion Method, which is identified by plotting the distance between each point and its closet centroid or Sum of Squared Error (SSE) in the Y axis, and the number of clusters in the $\mathrm{X}$ axis, as depicted in Fig. 4. The circle indicates the elbow point at which a significant change in SSE value occurs before the line slowly flattened; consequently, the appropriate cluster solution is 4. Then, the four clusters of traveler profiles are analyzed. Table 7 summarizes characteristics of each commuter segments, reporting mean with standard deviation of attitudinal variables, socioeconomic and trip variables.

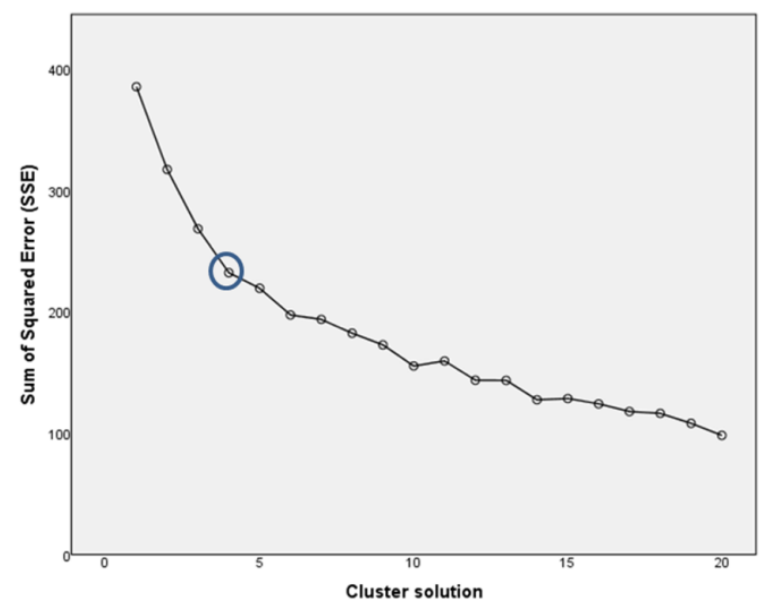

Fig. 4. Elbow criterion method.

The first cluster includes 93 individuals and it is the largest one (40\%). Mostly, approximately $68 \%$ of commuters in this group earn the income ranging from 0-19,999 Baht per month. $86 \%$ of the members are secondary or university graduates. Majority $(72 \%)$ are of the age below 40 . About $62 \%$ of the individuals make their trips over one kilometer. One-third of them travel longer than 10 minutes and half of them need to transfer. Commuters forming this group are highly satisfied with reliability, in-vehicle environment, comfort, and convenience of the service, making them 'pleasurable experience'. Users in this cluster are $43 \%$ and $57 \%$ from West and East BKK route, respectively.

The second cluster is the smallest one. It contains 39 individuals (17\%) characterized by the lowest reliability satisfaction of all. $77 \%$ of the members receive monthly income ranging from $0-19,999$ Baht. 
About $64 \%$ of the members are secondary or university graduates. Nearly half of them are above 40 years old. $36 \%$ of the members travel over 10 minutes. Most of their trips are long direct journey with the highest proportion of travel distance over one kilometer $(82 \%)$ and trips with no transfer $(69 \%)$. Accordingly, the reliability aspects are of high importance for them and this cluster is labeled as 'reliability oriented. Three-quarter of the group are users from West BKK route.

Table 7. User profiles of each cluster.

\begin{tabular}{|c|c|c|c|c|c|}
\hline Variables & & Pleasurable experience & Reliability oriented & In-vehicle environment desire & Environmentally conscious \\
\hline \multirow[t]{2}{*}{ Reliability } & Mean & 4.50 & 3.37 & 4.48 & 4.56 \\
\hline & SD & 0.04 & 0.08 & 0.06 & 0.07 \\
\hline \multirow[t]{2}{*}{ In-vehicle environment } & Mean & 4.15 & 3.27 & 2.69 & 3.70 \\
\hline & SD & 0.04 & 0.08 & 0.09 & 0.09 \\
\hline \multirow[t]{2}{*}{ Comfort and convenience } & Mean & 4.14 & 3.41 & 3.74 & 4.02 \\
\hline & SD & 0.06 & 0.10 & 0.09 & 0.09 \\
\hline \multirow[t]{2}{*}{ Environmental awareness } & Mean & 3.45 & 3.15 & 3.38 & 1.74 \\
\hline & SD & 0.06 & 0.08 & 0.09 & 0.07 \\
\hline \multirow{2}{*}{$\begin{array}{l}\text { Age } \\
(>40=1)\end{array}$} & Mean & 0.29 & 0.46 & 0.47 & 0.31 \\
\hline & SD & 0.05 & 0.08 & 0.07 & 0.07 \\
\hline \multirow{2}{*}{$\begin{array}{l}\text { Education } \\
\text { (Secondary or higher=1) }\end{array}$} & Mean & 0.86 & 0.64 & 0.85 & 0.88 \\
\hline & SD & 0.04 & 0.08 & 0.05 & 0.05 \\
\hline \multirow{2}{*}{$\begin{array}{l}\text { Monthly income } \\
(>20,000 \mathrm{Baht}=1)\end{array}$} & Mean & 0.32 & 0.23 & 0.49 & 0.45 \\
\hline & SD & 0.05 & 0.07 & 0.07 & 0.07 \\
\hline \multirow{2}{*}{$\begin{array}{l}\text { Travel distance } \\
(>1 \mathrm{~km}=1)\end{array}$} & Mean & 0.62 & 0.82 & 0.66 & 0.59 \\
\hline & SD & 0.05 & 0.06 & 0.07 & 0.07 \\
\hline \multirow{2}{*}{$\begin{array}{l}\text { Travel time } \\
(>10 \text { min }=1)\end{array}$} & Mean & 0.32 & 0.36 & 0.53 & 0.29 \\
\hline & SD & 0.05 & 0.08 & 0.07 & 0.07 \\
\hline \multirow{2}{*}{$\begin{array}{l}\text { Transfer } \\
\text { (Need transfer }=1 \text { ) }\end{array}$} & Mean & 0.51 & 0.31 & 0.60 & 0.45 \\
\hline & SD & 0.05 & 0.07 & 0.07 & 0.07 \\
\hline West BKK & $\%$ & 43 & 74 & 62 & 35 \\
\hline East BKK & $\%$ & 57 & 26 & 38 & 65 \\
\hline \multirow[t]{2}{*}{ Cluster size } & $\mathrm{n}$ & 93 & 39 & 53 & 49 \\
\hline & $\%$ & 40 & 17 & 22 & 21 \\
\hline
\end{tabular}

The third cluster made up by 53 individuals (22\%) revealing the lowest value on in-vehicle environment satisfaction. At the same time, this cluster shows inferior satisfaction on service comfort and convenience. Half of the commuters in this group earn monthly in come over 20,000 Baht and most of them (85\%) are secondary or university graduates. Among all groups, this group includes the highest proportion of people over 40 years old $(47 \%)$. It is found that $66 \%$ of the members make trips over one kilometer. This group reports the highest proportion of transfer trip $(60 \%)$ as well as trip duration over 10 minutes (53\%). Thus, in-vehicle environment, comfort and convenience of the service are considered essential factor when choosing the service. These individuals can be named 'in-vehicle environment desire'. Two-thirds of the users in this group are from West BKK route.

The last cluster includes 49 individuals $(21 \%)$ characterized by the lowest score on environmental attitudes. Nearly half of the members (45\%) are in the upper economic strata with the income above 20,000 Baht per month. Majority of people (88\%) are secondary or university graduates. $69 \%$ are users of age 40 or below. Almost half of the members (45\%) travel with the need to transfer. $50 \%$ of the trips are over one kilometer and mostly (71\%) are in short duration, 0-10 minutes. In general, they satisfied with reliability, in-vehicle environment, comfort and convenience of the service. What makes them distinct from other groups is their environmental awareness. From their perspectives, SR causes impact on pollution, 
traffic congestion, and accidents, though at low level, while other groups are more likely to be neutral for this issue. This cluster is then named 'environmentally conscious'. It is found that two-thirds of users in this group are from the East route.

\section{Discussion}

\subsection{Factors Influencing Perceived Satisfaction of SR Service}

Result from ordinal logistic regression model explains the way perception towards service quality affect customers' overall satisfaction. The four factors that have a significant effect on customer overall satisfaction are reliability, in-vehicle environment, comfort and convenience as well as environmental impact. Three factors, i.e. reliability, in-vehicle environment, comfort and convenience are in line with previous research results. Dell'Olio et al. [38] explored bus service quality in Spain and found that users most valued wait time, cleanliness, and comfort. These three variables can be viewed as aspects of reliability, in-vehicle environment, and comfort and convenience respectively. Our results confirm the significant effect of reliability on overall satisfaction for customers of both routes. Such finding is conforming to previous study on service quality of paratransit in developing countries in that reliability is one of the most significant observed variables having influence on the service [13]. Polat [39] argued that reliability refers to the degree of dependability on and trust-ability of passengers in a specific mode of transport and PT services. It also includes features such as accessibility and confidence. Passengers should be able to depend on those services and be able to see that they are obtainable on regular basis and are long termed. Besides, Cantwell et al. [40] reported that commuters travelling on an unreliable public transport service experience lower levels of commute satisfaction than those who commute on a reliable service. The longer time a respondent spends travelling, the lower the satisfaction level with their commute. According to the study on overall view of perceived total quality formed by the various groups of respondents [41], all public transport passengers valued most the availability and reliability of the service while the value-added quality factors come in second. However, the diverse results were found in the context of Indonesian bus services [17], where safety and comfort were, instead, the dominant factors influencing customer satisfaction. Therefore, when comparing among international contexts, local factors, such as cultural values and transport operational characteristics must be taken into account.

The previous studies on bus transit in Scotland indicated that in-vehicle environment and convenience displayed moderately strong significant correlation coefficients with perceived satisfaction [42]. Our study reports in a similar way that the aspects associated with in-vehicle environment significantly influence the overall satisfaction in the West route. It can be said that, with the longer average trip distance of 4.52 kilometers in West BKK route, the in-vehicle environment seems to be important factor for riders when choosing transport service. Comfort, convenience and environmental impacts are also significant factors in evaluating overall satisfaction only for customers of the East route. In fact, most East route users $(60 \%)$ need to transfer. It can be inferred that users with the need to transfer pay much attention to comfort and convenience aspects; consequently, they use these factors to evaluate their overall satisfaction of the service. This result supports the previous literature in that comfort has some value for travellers in spite of varying degrees in different circumstances [39]. Gebeyehu and Takano [43] demonstrated that transfer is a convenience factor when making connecting trips for bus travellers. Further, the environmental awareness shows significantly negative effect on their overall satisfaction on the service in East BKK route. $56 \%$ of users in the East route are university graduates and $51 \%$ of them earn monthly income of over 20,000 Baht. The education and income level could positively affect their understanding and awareness on environmental threats. This result is consistent with the study of the way education and income level influence people's environmental awareness by Yilmaz et al. [44] and Marquart-Pyatt [45].

\subsection{Heterogeneity of SR Commuter Segments}

Socioeconomic and travel behavior are found to influence the way commuters perceived SR service. From our findings, young riders tend to be more satisfied with the quality of service, as illustrated in 'pleasurable experience' and 'environmentally conscious'. This finding shares a common trend with Antoniou and Tyrinopoulos [46], which reported that younger people are in general more satisfied with the services, possibly because they are in good physical shape. This may affect comfort and convenience particularly when boarding and alighting the vehicle, waiting for the service, or sitting in the compact cabin space. 
However, in a case of formal public transport context, students of age group below 18 expressed the lowest satisfaction on bus services while the age group of 45-54 had high satisfaction [47]. The adverse evidence was likely due to the formality of vehicle design and operation which the accessibilities are standardized and convenience are signified.

Considering the trip characteristics, Hu et al. [48] revealed that for long distance trips, passengers are not satisfied with reliability or comfort of buses. This study supports the previous study in that commuters travelling long distance with no transfer, as presented in 'reliability oriented', pay much attention to reliability attributes. Wardman [49] pointed out that when journey distance increase, fatigue, boredom and discomfort set it. The findings in this study also report that commuters travelling longer duration need better cabin environment, as described for 'in-vebicle environment desire'. Apart from having high proportion of long distance trips, high proportion of transfer trips and older users over 40 years old are found as well. The study on bus traveler's satisfaction in Ethiopia suggested that transfer is a convenience factor when making connect trips [43]. So, the level of required convenience increases with the need to transfer. Additionally, older people were found to express dissatisfaction with bus design which may reflect their inability to step on/off the buses. Buses with high steps makes difficult to older people to board and alight [43]. This study also supports the previous literatures that 'in-vehicle environment desire', which comprises higher proportion of older users, prefer the service with more comfort and convenience, i.e. seat comfort, convenience of transfer, shelter and bench at stops, sufficient time to board and alight, ease to enter the vehicle, safety and security as well.

Among the four clusters, 'environmentally conscious' is the only group that is aware of the impact of SR on pollution, traffic congestion and accidents, though at low level, while other groups seem to be neutral on this matter. When compared to 'reliability oriented', their average incomes are in the upper economic strata with the higher proportion of secondary or university graduates. Yilmaz et al. [44] stated that with the rising of education level, people have improved ability to comprehend complex environmental problems as a result of higher level of awareness of public affairs based on increasing cognitive skill. Thus, the higher levels of education raise environmental awareness [50]. Marquart-Pyatt [45] investigated the measure of environmental concern in terms of awareness of environmental threats and education was revealed as a key factor in the expression of environmental concern. The result in current study also supports Ustun and Celep [51] that socioeconomic structures affect environmental awareness of people. Poorly-educated people do not show a lower level of environmental concern when compared to responds of people who are high school or university graduates. In addition, the similar relationship has been seen between people who are in the lower and upper income strata. Marquart-Pyatt [45] also stated that environmental concern is positively associated with income. The priorities of lower income people are more likely to meet the basic needs of their own and families and concern for environmental issues can be ignored when compare with meeting their basic needs. Nonetheless, higher income people have the proper conditions for meeting the basic needs such as adequate nutrition or health care [44]. That is why it is much more possible to be interested in environmental issues for them when compared to the lower income people.

\subsection{Policy Implications for SR Services}

Beside theoretical contributions, this study is useful in its provision of managerial implication. Firstly, when it comes to improving service quality of SR, the result suggests transportation planners to concentrate on dimensions of reliability, in-vehicle environment, comfort and convenience, and environmental impact. Second, based on SR user segmentation, they should pay attention to the differences in users' need regarding user profile and trip patterns existing in each service area.

Due to the fact that 'reliability oriented' have high needs of reliable, comfort and convenient service, managing the frequency of service especially during peak period to sufficiently serve the travel demand would increase the service quality and reduce the waiting time. Besides, integration of multimodal transfer infrastructures and facilities, such as shelters and benches, would enhance seamless transfer and improve the comfort and convenience of the service. As mentioned by Polat [39], the integration of public transport would increase the service quality. These could be effective ways to increase the ridership.

As particular preferences are illustrated in 'in-vehicle environment desire', vehicle designs and seating structures should be observed. Standards should be set up for aspects of seating condition, cabin space, and structures for protection from elements. Also, drivers should have participated in trainings for public service industry. These strategies could improve the quality of service and increase the overall satisfaction. 
Lastly, 'pleasurable experience' and 'environmentally conscious' have already shown high satisfaction level on the service quality. The best way is to keep up with the existing level of service; nonetheless, improving any service aspects would possibly exceed their expectations.

\section{Conclusion}

The study applied customer segmentation approach for the analysis of SR users. The attitudes towards SR service quality were extracted from attitudinal questions in customer survey of two SR routes in Bangkok. The factor analysis and ordinal logistic regression were employed to identify latent variables and determine how each variable influences the overall satisfaction of the users. The K-means clustering method was then used to segment SR users into four subgroups defined based on different attitudes towards service quality. The contribution of this study is that the presented framework can be utilized to identify the areas of quality concerns based on the variables of each route and also to suggest policy options for service improvement. It can be used to provide in-depth assessment of particular requirements of individual routes.

This study illustrates significant degree of interactions between the four service factors and overall satisfaction, indicating that SR customers consider these issues when evaluating their perceived service quality. From route-based perspective, 'reliability' seems to be the key factor that travelers in both routes concerned with. Interestingly, the 'in-vehicle environment' is the main issue only for customers of West BKK route while 'comfort and convenience' as well as 'environmental impact' are the significant aspects only for users of East BKK route. In fact, the more satisfaction level on these service factors, the higher the overall satisfaction was found. However, the exception is revealed in the case of environment attitude where the effect was inversed. That is, the less users perceived the environmental impact, the more they are satisfied with the overall service quality. To summarize, reliability, in-vehicle environment, comfort and convenience, and environmental impact represent useful indicators of customer satisfaction. In developing policies and strategies to maintain SR ridership, the government and transport authorities should prioritize the aspects of each route to best serve the user needs.

From system-based viewpoint, the result illustrated that segmentation approach was practical in capturing the heterogeneity among SR users. The four user subgroups with different features provide the understanding of how different socioeconomic and trip characteristics and attitudes are interrelated. Younger riders seem to be more satisfied with quality of SR service, while the older prefer the service with comfort and convenience. Additionally, people in the higher economic strata and education level pay attention to environmental issues. Some have particular desires when travelling in different circumstances. Long distance travellers with no transfer pay much attention to reliability, whereas commuters travelling for a long duration desire for better in-vehicle environment. The segmentation approach in this study can be applied by local authorities to identify SR user subgroups in Bangkok. Thus, policies can be developed regarding the specific features of SR subgroups. This study provides foundations for decision makers to act on the transport service quality in order to deliver a better transport service to commuters.

There are still opportunities for SR services in Bangkok to improve the service quality in order to maintain ridership as well as to attract potential users. To extend the study, future work can conduct the survey on non-users of SR. In fact, non-users can be potential users and they can be attracted by service improvement. How they are different from the users, in aspects of personal profiles and travel behavior as well as their attitudes towards SR service, can be explored. Thus, appropriate strategies for promoting SR commuting can be developed based on their attitudes and preferences as to enhance the use of public transport for sustainability of the city.

\section{Acknowledgements}

We gratefully acknowledge the financial support from the $100^{\text {th }}$ Anniversary Chulalongkorn University Fund for Doctoral Scholarship and the 90 th Anniversary of Chulalongkorn University Fund (Ratchadaphiseksomphot Endowment Fund). We also thank the survey team at Transportation Division of Civil Engineering Department, Chulalongkorn University for assistance in data collection. 


\section{References}

[1] Office of Passenger Transport, Department of Land Transport (DLT). (2018, May 7). Silor routes and vebicles registered in Bangkok as of February 2018. Personal interview.

[2] K. Choocharukul and K. Sriroongvikrai. (2011). "Service characteristics of informal public transport: A case of Bangkok's small-sized converted pickup trucks," Proceedings of the Eastern Asia Society for Transportation Studies, vol. 8. [Online]. Available: https://www.jstage.jst.go.jp/article/eastpro/2011/0/2011_0_188/_pdf [Accessed: 5 March 2018]

[3] Department of Land Transport and Transport Institute, "Current situation of Silor-lek transport mode in Bangkok," Ministry of Transport and Chulalongkorn University, Bangkok, 2009.

[4] T. B. Joewono, D. S. Santoso, and Y. O. Susilo, "Paratransit transport in Indonesia: Characteristics and user perceptions," Journal of the Eastern Asia Society for Transportation Studies, vol. 11, pp. 1346-61, 2015.

[5] N. Eung and K. Choocharukul, "Modeling frequency of using informal public transport and public bus: A case study in Phnom Penh, Cambodia," Engineering Journal, vol. 22, no. 3, pp. 109-22, 2018.

[6] A. Tangphaisankun, T. Okamura, and F. Nakamura, "Study on influences of paratransit on mass transit connectivity in developing countries: A case study of Bangkok," J Jpn Soc Civil Eng, vol. 26, no. 4, pp. 781-790, 2009.

[7] T. Okamura, Y. Kaneko, F. Nakamura, and R. Wang, "Passengers' attitudes to the service items of Jeepneys in Metro Manila by different lifestyles," Journal of the Eastern Asia Society for Transportation Studies, vol. 10, pp. 1384-95, 2013.

[8] Transportation Research Board (TRB), A Handbook for Measuring Customer Satisfaction and Service Quality. Washington DC: Transportation Research Board, 1999.

[9] J. De Ona and R. De Ona, "Quality of service in public transport based on customer satisfaction surveys: A review and assessment of methodological approaches," Transportation Science, vol. 49, no. 3, 2014. [Online]. Available: http://digibug.ugr.es/bitstream/handle/10481/34480/2015\%20TRANSP\%20SCIENCE\% 20review\%20SQ.pdf?sequence $=1$ [Accessed: 11 November 2018]

[10] I. Ajzen, "From intentions to actions: A theory of planned behavior," in Action Control: From Cognition to Behavior, Heidilberg, Germany: Springer, 1985, pp. 11-39.

[11] I. Ajzen and N. G. Cote, "Attitudes and the prediction of behavior," in Attitudes and Attitude Change, New York: Psychology Press, 2008, pp. 289-311.

[12] V. K. Phun and T. Yai, "State of the art of paratransit literatures in asian developing countries," Asian Transport Studies, vol. 4, no. 1, 57-77, 2016.

[13] F. Rahman, T. Das, M. Hadiuzzaman, and S. Hossain, "Perceived service quality of paratransit in developing countries: A structural equation approach," Transp Res A, vol. 93, pp. 23-38, 2016.

[14] I. G. M. Y. Bakti and S. Sumaedi, "P-TRANSQUAL: A service quality model of public land transport services," Int J Qual Reliab Manag, vol. 32, pp. 534-558, 2015.

[15] P. P. Sarkar and C. Mallikarjuna, "Effect of perception and attitudinal variables on mode choice behavior: A case study of Indian city, Agartala," Travel Behav Soc, vol. 12, pp. 108-114, 2018.

[16] T. B. Joewono and H. Kubota, "Transportation: Safety and security improvement in public transportation based on public perception in developing countries," LATSS Research, vol. 30, pp. 86-100, 2006.

[17] A. K. M. Tarigan, "Segmentation of paratransit users based on service quality and travel behavior in Bandung, Indonesia," Transport Plan Techn, vol. 37, no. 2, pp. 200-218, 2014.

[18] Bangkok Metropolitan Administration (BMA). (2015). Demographic record and area of districts in Bangkok. 2015. Strategy and Evaluation Department. [Online]. Available: http://www.bangkokgis.com/gis_information/population/ [Accessed: 20 November 2017]

[19] National Statistical Office (NSO). (2009). Indicator in poverty map. Ministry of Digital Economy and Society. [Online]. Available: http://service.nso.go.th/nso/nsopublish/poverty/poverty.html [Accessed: 20 November 2017]

[20] D. Grujicic, I. Ivanovic, J. Jovic, and V. Dovic, "Customer perception of service quality in public transport," Transport, vol. 29, no. 3, pp. 285-95, 2014.

[21] K. N. Habib, L. Kattan, and M. T. Islam, "Model of personal attitudes towards transit service quality," J Adv Transport, vol. 45, no. 4, pp. 271-85, 2011.

[22] N. Eung, "Travel behavior and factors influencing frequency of using informal transport and public bus in urban area of Phnom Penh," M.Eng. thesis, Chulalongkorn University, Thailand, 2015.

[23] G. Mazzulla and L. Eboli, "A service quality experimental measure for public transport," Eur Transp, vol. 34, pp. 42-53, 2006. 
[24] T. B. Joewono and H. Kubota, "User satisfaction with paratransit in competition with motorization in Indonesia: Anticipation of future implications," Transportation, vol. 34, no. 3, pp. 337-54, 2007.

[25] M. Yarmen and S. Sumaedi, "Perceived service quality of youth public transport passengers," Transp Probl, vol. 11, no. 1, pp. 99-111, 2016.

[26] M. Susilawati and D. P. E. Nilakusmawati, "Study on the factors affecting the quality of public bus transportation service in Bali Province using factor analysis," Journal of Physics: Conference Series, vol. 855, no. 1, p. 012051, 2017. [Online]. Available: http://iopscience.iop.org/article/10.1088/1742-6596/855/1/012051/pdf [Accessed: 11 May 2018]

[27] P. Sharma, J. K. Jain, and S. Reddy, "Analysis of service quality attributes for Jaipur Urban Bus Transportation," IJET, vol. 8, no. 1, pp. 43-48, 2017.

[28] C. Pronello and C. Camusso, "Travellers' profiles definition using statistical multivariate analysis of attitudinal variables," Journal of Trans Geog, vol. 19, pp. 1294-1308, 2011.

[29] J. Anable, “'Complacent car addicts' or 'aspiring environmentalists'? Identifying travel behavior segments using attitude theory," Transp Policy, vol. 12, pp. 65-78, 2005.

[30] T. Ryley, "Use of non-motorized modes and life stage in Edinburgh," Journal of Trans Geog, vol. 14, pp. 367-375, 2006.

[31] M. Sarstedt and E. Mooi, "A Concise Guide to Market Research," in Springer Texts in Business and Economics, Berlin Heidelberg, Germany: Springer-Verlag, 2014.

[32] D. R. Lehmann, S. Gupta, and J. H. Steckel, Marketing Research. Reading, MA: Addison-Wesley, 1998.

[33] J. Kim and C. W. Mueller, "Introduction to Factor Analysis: What It Is and How to Do It. Beverly Hills, Calif.: Sage, 1990.

[34] B. G. Tabachnick and L. S. Fidell, "Principal components and factor analysis," in Using Multivariate Statistics, 6th ed. New Jersey: Pearson Education, 2013, ch.13.

[35] R. Cornish, "Cluster Analysis," in Mathematics Learning Support Center: Statistics. 2007. [Online]. Available: http://www.statstutor.ac.uk/resources/uploaded/clusteranalysis.pdf [Accessed: 21 May 2018]

[36] A. B. Costello and J. W. Osborne, "Best practices in exploratory factor analysis: Four recommendations for getting the most from your analysis," Pract Assess Res Eval, vol. 10, no. 7, pp. 1-9, 2005.

[37] F. C. Pampel, Logistic Regression: A Primer. Thousand Oaks, CA: Sage, 2000.

[38] L. Dell'Olio, A. Ibeas, and P. Cecin, "The quality of service desired by public transport users," Transp Policy, vol. 18, no. 1, pp. 217-227, 2011.

[39] C. Polat, "The demand determinants for urban public transport services: A review of the literature," $J$ Applied Sci, vol. 12, no. 12, pp. 1211-1231, 2012.

[40] M. Cantwell, B. Caulfield, and M. O'Mahony, "Examining the factors that impact public transport commuting satisfaction," J Public Trans, vol. 12, no. 2, pp. 1-21, 2009.

[41] K. Vanhanen and J. Kurri, (2005). "Quality factors in public transport," Transport Today and Tomorrow: Promoting sustainable transportation in Israel, WSP Finland Ltd and Helsinki University of Technology. [Online]. Available: http://transportation.org.il/en/node/3017 [Accessed: December 2018]

[42] C. Morton, B. Caulfield, and J. Anable, "Customer perceptions of quality of service in public transport: Evidence for bus transit in Scotland," Case Stud Transp Policy, vol. 4, pp. 199-207, 2016.

[43] M. Gebeyehu and S. Takano, "Modeling the relationship between travelers' level of satisfaction and their mode choice behavior using ordinal models," JTRF, vol. 47, no. 2, pp. 103-118, 2008.

[44] S. Yilmaz, S. Yaman, and I. Alkaya, "The impact of socio-economic structure on environmental awareness in Kucukcekmece Basin,” B.Sc. Thesis, Yildiz Technical University, Turkey, 2006.

[45] S.T. Marquart-Pyatt, "Environmental concerns in cross-national context: How do mass publics in central and eastern Europe compare with other regions of the world?," Sociol Cas, vol. 48, no. 3, pp. 641-666, 2012.

[46] C. Antoniou and Y. Tyrinopoulos, "Factors affecting public transport use in touristic areas," International Journal of Transportation, vol. 1, no. 1, pp. 91-112, 2013.

[47] J. Weng, X. Di, C. Wang, J. Wand, and L. Mao, "A bus service evaluation method from passenger's perspective based on satisfaction surveys: A case study of Beijing, China," Sustainability, vol. 7, no. 2723, pp. 1-15, 2018.

[48] X. Hu, L. Zhao, and W. Wang, "Impact of perceptions of bus service performance on mode choice preference," Advances in Mechanical Engineering, vol. 7, no. 3, p. 1687814015573826, 2015. [Online]. Available: https://doi.org/10.1177/1687814015573826 [Accessed: 12 December 2018]

[49] M. Wardman, "Public transport values of time," Transp Policy, vol. 11, pp. 363-377, 2004. 
[50] G. Movsesyan and E. Zagheni. (2014). "How do demographic factors influence environmental attitudes?," Population Association of America: 2014 Annual Meeting Program. [Online]. Available: http://paa2014.princeton.edu/ papers/143239 [Accessed: 9 November 2018]

[51] B. Ustun and B. Celep, "The connection between environmental awareness and socio-economic and cultural structure," WIT Trans Ecol Envir, vol. 102, pp. 621-631, 2007. 